\title{
OPEN EDUCATIONAL RESOURCES: A REVIEW OF ATTRIBUTES FOR ADOPTION IN AN ONLINE BACHELOR'S DEGREE PROGRAM
}

\author{
Patricia Neely, Higher Learning Institute \\ Jan P. Tucker, Higher Learning Institute \\ Angela Au, Higher Learning Institute
}

\begin{abstract}
As concerns about the skyrocketing costs of a college degree have converged with the increasing availability of open educational resources (OER), higher education administrators are asking faculty and curriculum designers to use OERs to design courses and programs. This case study explores the decision making process and outcomes of an online, for-profit university's attempt to build low-cost business degree programs using open educational resources. The paper concludes with a list of suggested criteria for evaluating open source content when designing similar programs.
\end{abstract}

Keywords: open educational resources, open source content, curriculum design, course development, decision making

\section{INTRODUCTION}

Open Educational Resources are defined as "teaching, learning and research materials in any medium that resides in the public domain and have been released under an open license that permits access, use, repurposing, reuse and redistribution by others with no or limited restrictions," (Atkins, Brown, \& Hammond, 2007, p. 7). Open educational resources can include full courses, degree programs, course materials, modules, syllabi, teaching notes, textbooks, research articles, podcasts, videos, assessments, simulations, databases, software applications, and various other types of educational materials.

For most students and faculty members, textbooks are an integral part of the college classroom experience. Student budgets for an academic year include funds for buying textbooks with costs running $\$ 1,200$ or more per academic year per undergraduate student (Senack, 2014) equating to over $\$ 10$ billion being spent annually on textbooks (Green, 2013). Faculty instructors design courses around textbooks created by publishers who are often accused of changing editions to keep textbook prices high (Grasgreen, 2014). College textbook costs have increased over $80 \%$ in the past decade, four times the rate of inflation (Scholarly Publishing Resources and Academic Coalition, 2014). For students already struggling to pay college tuition and fees, which have risen 1000\% in the past 30 years (Jamrisko \& Kolet, 2012), textbook costs can hinder their goal of earning a college degree.

With public concern over escalating college costs, it is no surprise that colleges are looking at open educational resources (OER) as an opportunity to increase access for students, and allow students and institutions to save substantial amounts of money by reducing dependence on expensive textbooks (Bliss, Hilton, \& Wiley, 2013; Hilton \& Wiley, 2011).

In the past ten years, interest in OER has grown, driven not only by the high costs of college textbooks but also by government and public pressures over the high cost of a college degree and the inability of current educational institutions to 
meet the worldwide demand for higher education. Nearly two-thirds of all chief academic officers agree that open education resources have the potential to reduce costs at their institutions (Allen \& Seaman, 2012). Maricopa Community Colleges estimated that students could save over $\$ 700$ per semester (Fraulino, 2015). Supporters of open educational resources suggest that OER has the potential to lower the direct cost per institution of developing high quality learning materials, to provide unique opportunities for institutions to offer low enrollment courses and programs in a cost effective way, and to radically reduce textbook costs (Anderson \& Elloumi, 2004). In turn, this should improve "access to and quality of schooling for students, self-taught learners, educators, and institutions around the world," (The Hewlett Foundation, 2013, p. 6).

\section{OVERVIEW OF OPEN EDUCATIONAL RESOURCES}

Although free online textbooks are the most popular option among open educational resources, a variety of open resources are available including full courses, degree programs, simulations, articles, podcasts, videos, learning objects and software applications (MIT Open Courseware, 2014). When originally coined, the term OER referred to openly available materials and did not indicate that the materials needed to be available online or in digital format (UNESCO, n.d.). Resources had to be free for use, but they could be in formats that have to be printed rather than downloaded from the Internet.

The early beginnings of open educational options for students can be found in Great Britain's Open University, which was founded in 1969. Another strong supporter of OER is UNESCO, which first coined the term "open educational resources" in 2002. Within the United States, Massachusetts Institute of Technology (MIT) was an early supporter of OER, launching its Open Courseware Project in 2002. Other efforts around open resources include the Open Learning Initiative from Carnegie Mellon, Connextions from Rice University, the University of Leicester's OTTER Project and Harvard Extension School's Open Learning Initiative (Tucker, Neely, \& Belcher, 2013). The Creative Commons organization provides support for the use of open educational resources by developing copyright licenses for open materials as well as identifying and lowering barriers to research, data and materials (Creative Commons, 2014).

With the advent of the Digital Age, the terms open and OER are interpreted as meaning content is free for use and available over the Internet. Open means an ability to reuse (unaltered, as is), revise (adapt and modify the content, such as a translation), remix (combine the original content or revisions, creating something novel), and redistribute (share copies of the original, revised or remixed content) (Tucker, Neely, \& Belcher, 2013). Multiple types of users including faculty, instructional designers, subject matter experts, high school teachers, corporate trainers and learners can download OER. Once downloaded, OER can be used as an informal learning tool for students (e.g., Khan Academy videos) or integrated within a structured course environment. For example, a course may be designed around an OER instead of around a textbook or a course may offer a varied set of learning resources for students including purchased materials, such as a textbook and open material like white papers, reports or videotaped lectures. Each resource is issued under a license that spells out how it can be used.

Along with lowering the costs of producing a college degree, other potential benefits can be attributed to the creation and use of open educational resources. D'Antoni (2009) wrote that potential benefits of OER include making information available to all, widening participation in higher education by expanding access to nontraditional learners and learners worldwide and promoting lifelong learning. OER has been touted as a way to bridge the gap between formal and informal learning as well as leveraging taxpayers' money by sharing and reusing learning content between institutions (D'Antoni, 2009).

Open educational resources may reshape higher education, but significant challenges to the adoption of OER will need to be addressed first, including technical challenges, price/cost barriers, permission barriers, and limitations to the ability to adapt or build upon a resource (Open Knowledge, 2014). Early adopters of OER considered education to be a public good and suggested that openness can create positive change in education by improving student outcomes (The Hewlett Foundation, 2013). Furthermore, garnering administrative support for the integration of open resources and motivating 
faculty to change curriculum design processes can be challenging. Restrictive intellectual property policies, lack of time for educators to develop and remix OER, reward systems that fail to reward open educational activities, and a lack of strategic goals and leadership can impede the development and adoption of OER within an institution (Bissell $\&$ Boyle, 2007). In a 2012 survey of chief academic officers, Allen and Seaman (2012) found that, “... approximately one-half of institutions of all sizes, ranging from the very smallest (under 1500 total enrollments) to the very largest (with over 15,000 total enrollments) report that they currently use OER materials in their courses. This pattern of use by institutional size is consistent for all course delivery types - online, blended and face-to-face," (p. 7). In the past, learning resources developed by a university's faculty were considered intellectual property and a key differentiator in the educational experience at the institution. Today, there is movement toward openness in higher education with more and more institutions and individuals sharing their digital learning resources over the Internet openly and for free (Hylen, n.d).

\section{OPEN EDUCATIONAL RESOURCES AND THE BACHELOR'S IN BUSINESS PROGRAM}

In 2011, an investment group purchased a $100 \%$ online university (which will be referred to as OnlineU). After the purchase, OnlineU was re-branded as a low-cost, competency-based university. The mission of the university was to leverage new technologies to deliver high-quality, low-cost degree programs. The goal was to develop and deliver low-cost programs marketed to selfpaying students. Keeping course development and material costs minimized was critical to achieving the university's mission of keeping tuition low.

College administrators embarked on a major initiative with the re-creation of the 120- credit Bachelor of Business program in early 2012. Each of the current 40 courses was redesigned around competencies using free or low-cost open resources in place of the previous courses, which relied heavily on textbooks and supplemental materials provided by textbook publishers. Leading the redesign process was the academic dean along with the dean for the College of Business and the dean for the College of Arts and Sciences. The Provost, two faculty members, an instructional designer and a cadre of subject matter experts who will be referred to as the "work group" also provided support for the redevelopment of the program.

\section{EVALUATION OF SERVICE PROVIDERS USING SELECTION CRITERIA}

The first step in the evaluation process began with identifying the courses in the Bachelor of Science in Business program that would be converted to the new model in Phase 1 of the course redevelopment project. In Phase 1 of the project, only the courses required for the Bachelor of Science in Business with a concentration in Management/Leadership were re-developed. Phase 1 of the redevelopment process included 20 general education courses, 11 business core courses, nine Management/Leadership concentration courses, and three elective courses. The general education courses and elective courses were prescribed for this first phase of development.

The courses were selected based on enrollment projections as the Management/Leadership concentration was a popular degree track. Once the work group identified the courses and updated the course descriptions, the next step was for the group to scan the higher education environment for open or low-cost learning content. The work group identified potential OERs by performing general Internet searches and benchmarking other online degree programs. Table 1 includes a list of the resources reviewed. The selection criteria will be discussed in the next section of this case study. 
Table 1

Environmental Scan of OER Websites

\begin{tabular}{|c|l|l|}
\hline \multicolumn{1}{|c|}{ Resource } & \multicolumn{1}{|c|}{ URL } & \multicolumn{1}{|c|}{ Type } \\
\hline Merlot Online Courses & http://onlinecourses.merlot.org/ & Open courses \\
\hline Khan Academy & https://www.khanacademy.org/ & Open courses \\
\hline FutureLearn & https://www.futurelearn.com/ & Open courses \\
\hline OEDb & http://oedb.org/ & Open courses \\
\hline Open Textbook Library & http://open.umn.edu/opentextbooks/ & Textbooks \\
\hline OpenStax & http://openstaxcollege.org/ & Textbooks \\
\hline FlatWorld Knowledge & http://www1.flatworldknowledge.com/ & Textbooks \\
\hline OER Commons & https://www.oercommons.org/ & Games, readings, textbooks, videos \\
\hline Open Education Consortium & http://oerconsortium.org/discipline-specific/ & Textbooks \\
\hline
\end{tabular}

The third step in the process was to compile the information gathered into a report for the provost. The report included evaluation of each resource based upon criteria identified during the scanning process. The original list of 18 criteria expanded to 25 as listed in Table 2 when faculty members began actually examining the available resources.

The fourth step in the process was to narrow the list of possible providers. The college was operating on a six-month timeline and determined that the ideal provider would be willing to work within this timeline. The team selected three goals for the main content providers. The ideal provider would also supply content for both general education and business courses and be willing to allow the content to be uploaded into the college's learning management system (LMS). The list of selection criteria is listed in Table 2 . The group met to discuss the list of possible providers.

After the list of providers was narrowed down to providers who offered both general education and business content, phone conferences were held with identified providers to assess whether a relationship with the provider could be established. Representatives of the work group as well as the college's IT team participated in the meeting.

The final step in the evaluation process was to select a provider. The work group met with the provost, president and Vice President for IT Development to review the list of possible providers. FlatWorld Knowledge was selected as the content provider after an analysis of the criteria and the phone conferences were completed. Both the academic work group and the information technology team felt that FlatWorld Knowledge met the criteria and that the staff at FlatWorld Knowledge was very interested in building a relationship with the college.

\section{EVALUATION CRITERIA}

When the work group first began finding and evaluating open resources, they could not find any published list of evaluation criteria. Since no formal list existed, the work group had to create one. Basic parameters were established including that the provider be able to provide resources for both general education and business courses, offer content at the appropriate levels for both lower-level and upper-level courses, and be willing to allow content to be loaded and delivered in the college's new learning platform.

As the group began to evaluate available open learning content, four categories for evaluating resources emerged including technology, student experience, attributes and administration. Each of these categories represented potential barriers to development and implementation of the proposed degree program. Table 2 lists the criteria, by category, identified as crucial for the evaluation of potential resources. 
Table 2

Criteria and Evaluation

\begin{tabular}{|c|c|c|}
\hline Category & Criteria & Rating Scale 1-5 \\
\hline \multirow[t]{8}{*}{ Technology } & Integrates with Current Technology Systems (LMS, SIS, HR, etc.) & \\
\hline & Stable Platform Supporting the Resource & \\
\hline & Technical Support Available & \\
\hline & Low Set Up Costs & \\
\hline & Works with Mobile Technologies & \\
\hline & Information Security & \\
\hline & Ongoing Technical Support Required & \\
\hline & Collects and Shares Student Data (e.g. usage data, assessment data) & \\
\hline \multirow[t]{4}{*}{ Student Experience } & Look and Feel of Resource (readability, graphics, polished versus flat, etc.) & \\
\hline & Ease of Access and Use & \\
\hline & Single Sign-0n & \\
\hline & Access on Mobile Devices & \\
\hline \multirow[t]{6}{*}{ Learning Resource Attributes } & Alignment with Learning Outcomes & \\
\hline & Content Currency and Accuracy & \\
\hline & Content at Appropriate Level & \\
\hline & Flexibility to Adopt Entire Resource or Specific Sections & \\
\hline & Instructor Resources Available & \\
\hline & Reputation of Supporting Institution/Organization & \\
\hline \multirow[t]{7}{*}{ Administration } & Legal Concerns-ADA Compliant and Copyright & \\
\hline & Coordinator for Managing Resource & \\
\hline & Legal Relationship with Resource Provider & \\
\hline & Implications of a Relationship with Provider & \\
\hline & Ease of Administering the Resource & \\
\hline & Overall Costs of Adoption and Implementation & \\
\hline & Ongoing Administrative Costs & \\
\hline
\end{tabular}

The university was in the process of developing its own learning platform to support student learning and engagement so technology underlying open resources was an important consideration. The work group determined that the following was critical: open resources should be compatible with the new learning management system; the platform supporting the resource must be stable; the provider should have ongoing technical support; and there must be a system for protecting student privacy. Each group member was asked to score potential providers using the criteria provided in the ratings worksheet. For each criterion, a score of 1 to 5 was awarded. A score of 5 indicated that the resource met the criteria. A score of 1 indicated that the resource failed to meet the criteria. The scores on each criterion within each of the four resource categories were then averaged and rounded to the nearest whole number. An average score was compiled for each OER and the results are shown in Table 3:

Table 3:

Aggregate score of OER's evaluated

\begin{tabular}{|l|l|}
\hline Resource & Aggregate score \\
\hline FlatWorld Knowledge & 16 \\
\hline Merlot Online Courses & 8 \\
\hline FutureLearn & 10 \\
\hline Khan Academy & 10 \\
\hline OEDb & 14 \\
\hline OER Commons & 11 \\
\hline Open Education Consortium & 10 \\
\hline OpenStax & 13 \\
\hline Open Textbook Library & 11 \\
\hline
\end{tabular}


Providing a high quality student experience was important to the college, so criteria were developed to address this area. Criteria included readability of content, ease of use, single sign-on capability and access via mobile technologies were identified as important to creating a good student experience.

The attributes of the learning resources provided by each of the providers were evaluated. The alignment of learning content available with program competencies was important to meeting program outcomes. Currency of course content and the provider's processes for reviewing and updating content were a consideration. Flexibility in adopting chunks of content or entire resources was crucial to meeting design requirements. In order to build the reputation of the college as a high quality institution, identifying a provider who had a good reputation within the higher education industry was important.

Finally, administration of the learning content needed to be manageable. As a small start-up organization, the college had limited resources to support a relationship with a learning content provider. A provider was needed that had already addressed ADA requirements and who was reasonable in terms of contract requirements. Of course, costs for the resources were also a concern for the college as its goal was to provide a low-cost education for students.

After the main resource (usually a textbook) was selected, the work group focused on obtaining auxiliary resources such as video, open access journal articles and free licensed clipart. The goal was to provide scaffolding with the resources to appeal to various learning styles. In addition, checkpoint quizzes and short answer questions were integrated throughout the modules to allow students to self-check their comprehension of the topics. Students were able to take a pre-assessment at any time during the module to determine where they needed to focus their efforts before moving on to the graded assignments.

\section{LESSONS LEARNED}

Although there are many open resources available, there is no single warehouse listing for evaluating these option. Resources vary significantly in terms of quality and accessibility. Searching through the available resources was a time consuming process for the work group. Once a resource was located, evaluating whether it was a viable option meant requesting sign-on access, searching through course lists, opening courses/ textbooks, and reviewing course outcomes or tables of content. This initial review was only the first step. Once a resource was identified, additional faculty members and the dean undertook secondary reviews. Finding open resources for a single course can be manageable but trying to identify open or low-cost resources for an entire degree program is daunting. Rather than using a number of different providers, the work group opted to select a single low-cost textbook provider. The group quickly recognized that using a number of providers would have been unmanageable with the college's small staff. Even after selecting a single provider, significant faculty time was devoted to reviewing, selecting and adapting content within each textbook so that it could be uploaded into the learning management system.

Technical support needed for open or lowcost resources can be significant. Integrating the open resources into the learning management system required the support of both faculty and IT programmers. Information technology support for building single sign-on and addressing technical issues with content can be costly. For example, after OU's IT staff uploaded the content into the learning management platform and the faculty member revised it to meet the course competencies, there were still problems with the way the content was formatted. The format changes had to be made by one of the IT programmers. The IT staff also played a critical role in evaluating possible providers and supporting the faculty member during the content upload and modification processes.

During the selection process, the work group developed criteria to help ensure that the student experience using the resource was positive. After the courses were launched, many students complained that the resources made available to them did not align to the graded assignments. Student feedback on the courses often contained phrases such as "too much busy work" or that the exams "did not match the readings or videos." In some instances, the work group felt that they were force-fitting resources to the required material. Both the work group and students questioned the relevancy of some of the OERs. OnlineU had specific requirements for the number of resources that needed to be available 
in each class, and often this meant incorporating a resource that did not completely align with the content.

In addition, the work group quickly found out that a creative common license does not mean that a resource is without restrictions. Some of the videos incorporated in the classes had to be removed and the work group scrambled to create proprietary videos to avoid any licensing problems. A similar issue arose with some of the clipart placed in the online courses. Many of these images were removed and replaced with original photographs once again to avoid any potential licensing infringement that might occur. The open resource textbooks were not updated very often, if at all. Any problems found in the textbooks such as spelling or grammar issues or even content problems could not be easily rectified since OU did not own the material. Instructors were asked to direct students to the correct information when possible but this became cumbersome and difficult to maintain. In the end, OU decided to link a specific textbook from one of the major publishers to each course and use OERs to augment the material as needed.

Administration of open educational resources is not free. Most faculty members are not qualified to review the legal requirements of open educational resources. For example, many open educational resources were not viable options for OnlineU because OU is a for-profit entity. Open resources are often only usable by government or nonprofit entities. Open resources often have legal requirements around their usage. Some open resources must be used in their entirety and cannot be modified. To ensure that the open resources are truly open and can be used as a whole or in part, a college's legal team needs to review the fine print on open resource websites creating costs for the college. Additional administrative costs that may be incurred with open or low-cost resources include instructional designer costs for uploading the content into the learning management system. It is difficult to find a single provider with a range of materials. Using a number of providers is not feasible for a small, start-up college because of the administrative costs.

\section{CONCLUSION}

Availability and access to open educational resources is increasing. Institutions and learners can find a wide range of free, open content available in a variety of formats on the Internet. As the availability of OER continues to increase, university decision makers will face increasing pressures to use OER to lower the costs of developing courses and programs. The authors' experiences with using open education resources to develop a Bachelor of Science in Business degree exposed significant challenges with relying on OER to solve the skyrocketing cost of higher education.

Finding ways to use OER and meet institutional, educational, accreditation and student needs is challenging. The theory behind OERs is a noble one: Use technology to allow the world to create and share their knowledge. Unfortunately, the logistics and administrative issues associated with using OER are many. With increased scrutiny and accountability being placed on higher education institutions, most notably for-profit institutions, ensuring resources are valid, reliable and aligned with the stated course and program outcomes is imperative. OERs might not solve the cost issues of higher education but continuing to research this and other options may eventually lead to the solution.

\section{References}

Allen, I. E., \& Seaman, J. (2012). Growing the curriculum: Open education resources in U.S. higher education. Babson Survey Research Group. Retrieved from http://www. onlinelearningsurvey.com/reports/growingthecurriculum.pdf.

Anderson, T., \& Elloumi, F. (2004). Theory and Practice of Online Learning. Athabasca, CA: Athabasca University.

Atkins, D. E., Brown, J. S., \& Hammond, A. L. (2007, February). A Review of the open educational resources (OER) movement: Achievements, challenges, and new opportunities. A report to The William and Flora Hewlett Foundation.

Bissell, A., \& Boyle, J. (2007). Towards a Global Learning Commons: ccLearn. Educational Technology, 4(6), 5-9.

Bliss, T., Hilton, J., Wiley, D. \& Thanos, K. (2013). The cost and quality of open textbooks: Perceptions of community college faculty and students. First Monday, 18(1).

Creative Commons. (2014). http://creativecommons.org/about/ history.

D'Antoni, S. (2009). Open educational resources: Reviewing initiatives and issues. Open Learning: The Journal of Open and Distance Learning, 24(1), 3-10. 
Fraulino, S. (2015). Maricopa Millions: Saving students money with open educational resources. Maricopa Community Colleges. Retrieved from https://maricopa.instructure.com/ courses/811971/pages/infographic

Grasgreen, A. (2014, January 28). Options don't stem textbook woes. Inside Higher Education. Retrieved from http://www. insidehighered.com/news/2014/01/28/textbook-prices-stillcrippling-students-report-says\#sthash.g6PE2GpR.dpbs.

Green, S. (2013 November 17). Dan Rosenweig's crystal ball goes cloudy with Chegg IPO. Jewish Business News.

Hilton, J. \& Wiley, D. (2011, June). Open-access textbooks and financial sustainability: A case study on Flat World Knowledge. The International Review of Research in Open and Distance learning, 12(5).

Hylen, J. (n.d.). Open educational resources: Opportunities and challenges. OECD's Centre for Educational Research and Innovation. Retrieved from http://www.oecd.org/edu/ ceri/37351085.pdf

Jamrisko, M., \& Kolet, I. (2012, August 15). Cost of college degree in U.S. soars 12 fold: Chart of the day. Bloomberg Business. Retrieved from http://www.bloomberg.com

MIT Open Courseware. (2014). Retrieved from http://ocw.mit.edu/ index.htm

Open Knowledge. (2014). The open education handbook 2014. Open Education working Group..

Scholarly Publishing and Academic Resources Coalition. (2014). Open education week kick off with congressional briefing. [Press release]. Retrieved from http://www.sparc.arl.org/ news/open-education-week-kicks-congressional-briefing

Senack, E. (2014, January). Fixing the broken textbook market: How students respond to high textbook costs and demand alternatives. U.S. PRIG Education Fund. Retrieved from http://www.uspirg.org/sites/pirg/files/reports/NATIONAL\%20 Fixing\%20Broken\%20Textbooks\%20Report1.pdf.

The Hewlett Foundation. White Paper: Open Educational Resources. Retrieved from http://www.hewlett.org/ library/hewlett-foundation-publication/white-paper-openeducational-resources

Tucker, J., Neely, P. \& Belcher, T. (2013). Competency Based Education: A Solution to the Challenges Facing Higher Education in the 21st Century? In R. McBride \& M. Searson (Eds.), Proceedings of Society for Information Technology \& Teacher Education International Conference 2013 (pp. 10931098). Chesapeake, VA: AACE

UNESCO Institute for Statistics (n.d.). Higher education. Retrieved from http://www.uis.unesco.org/Education/Pages/tertiaryeducation.aspx

\section{Author Biographies}

Patricia Neely has an EdD from the University of Virginia, an MBA from Averett University and a BS degree from Radford University. Dr. Neely has a rich background in higher education administration including curriculum design and development, program management and faculty supervision roles. She specializes in the development of competency-based degree programs. Her work experience includes leadership roles at Western Governors University, Old Dominion University and Kaplan University. She is currently a higher education consultant specializing in competencybased education and resides in Pounding Mill, Virginia, with her family.

Jan Tucker has a PhD in Business Management from Northcentral University, an MBA from Florida Institute of Technology and a BA degree in Psychology from Auburn University. Dr. Tucker has over 25 years' experience in higher education in the areas of instruction and curriculum development, over half of which have been in distance education. She has developed undergraduate and graduate courses in Management, HR, Organizational Behavior, Marketing, Finance, Research and Design and similar disciplines. In addition, she spent over 10 years as a Human Resources consultant for several Fortune 500 companies. Her research interests include the integration of technology in education, disruptive innovation in higher education and change management processes. She currently resides in Tampa, Florida, with her family.

Angela Au Angela has a DBA in social media marketing, a Master Certificate in Educational Technology from Northern Arizona University and a BA degree in Communication Studies from Seattle University. Dr. Au has extensive experience in competency-based education, online learning, instructional design and small business marketing. Since 2000, she has worked for various higher 
education institutes including community colleges, not-for-profit and for-profit universities. She has also assisted many small business owners with strategies as a marketing consultant. Angela lives in Tucson, Arizona, with her husband and their pets. 